\title{
Philosophiques
}

\section{À propos de Moïse}

Deux notes de recherche

\section{Tertius Chandler}

Volume 22, numéro 2, automne 1995

URI : https://id.erudit.org/iderudit/027334ar

DOI : https://doi.org/10.7202/027334ar

Aller au sommaire du numéro

Éditeur(s)

Société de philosophie du Québec

\section{ISSN}

0316-2923 (imprimé)

1492-1391 (numérique)

Découvrir la revue

\section{Citer cette note}

Chandler, T. (1995). À propos de Moïse : deux notes de recherche. Philosophiques, 22(2), 297-299. https://doi.org/10.7202/027334ar d'utilisation que vous pouvez consulter en ligne.

https://apropos.erudit.org/fr/usagers/politique-dutilisation/ 


\title{
À PROPOS DE MÖ̈SE* DEUX NOTES DE RECHERCHE
}

\author{
par \\ Iertius Chandler
}

\section{Une erreur de Moïse}

Comme Manéthon et plusieurs historiens après lui l'ont enseigné, Moïse a sans doute vécu à l'époque du pharaon Akhnaton. Certains l'ont donc identifié à Ramose, le puissant vizir d'Akhnaton qui aurait abrégé son nom comme il le devait, en tant que monothéiste dévoué à Aton (Adonaii). Si l'on poursuit l'hypothèse dans ce sens, Moïse aurait été présent au moment où prenait forme la foi en Aton.

Dans son zèle pour se défaire des anciens prêtres afin de pouvoir instaurer la nouvelle foi et les réformes qui l'accompagnaient - tel le jour de repos hebdomadaire - , Moïse avait réussi à persuader le pharaon Akhnaton de déclarer fermés les anciens temples. Il n'en avait cependant fait ouvrir plus tard que sept nouveaux, ce qui, naturellement, offensa plusieurs personnes pieuses. Il y a là un paradoxe, une contradiction inhérente entre la foi professée et l'acte posé. La foi de Moïse se fondait sur la règle d'or : « Tu aimeras ton prochain comme toi-même » (Lévitique 19 : 18). Pourtant, de fermer le temple d'autrui n'est guère un acte d'amour, même si cet acte repose sur les meilleures intentions. Cette façon d'agir ne repose en fait que sur une pure présupposition : passer outre aux désirs d'autrui au nom du mieux collectif sera aussi le mieux pour le bien individuel.

Examinons de près ce qui est en jeu ici. Les prêtres, composant l'élément le plus conservateur de la société à cette époque, réussissaient à contrer

* NDRL. Tertius Chandler, maintenant à la retraite, est l'auteur de Three Thousand Years of Urban Growth (avec une préface de Lewis Mumford) et de Thousand Years of Urban Growth. Ses recherches actuelles portent principalement sur la vie de Moüse, que, dit-il, « je considère comme le grand champion de l'homme moyen, lui qui a établi le jour de repos, instauré la règle d'or, prôné un code de lois qui ne pose aucune distinction entre les classes sociales et cherché à rendre libres tous les esclaves. Je lui attribue même la démocratie, avec son conseil des â̂nés, jusque là inconnu dans l'histoire égyptienne. ». 
efficacement certaines réformes que Moïse souhaitait entreprendre. Néanmoins, celui-ci les attaquait uniquement en raison de leur polythéisme. Bien entendu, si la nature est la seule véritable force de l'univers, on se trompe quand on pose l'existence, non seulement d'une pluralité de dieux, mais aussi d'un Dieu unique. Dans ce cas, ce serait donc la vie humaine, ici sur terre, que nous devrions révérer. C'est peut-être ce que Moïse a voulu transmettre. Qu'il ne fasse jamais aucune mention de l'au-delà nous le laisserait certainement penser, tout comme les violentes diatribes qu'il dirige contre les prophètes et les devins (Deutéronome $13: 1-5$ et $18: 10-12$ ).

D'après la Bible, Moïse serait allé bien plus loin que de fermer des temples. Il aurait été responsable de la condamnation à mort de ceux qui croyaient fidèlement en un dieu autre que le sien (Deutéronome 7 et 20). Moïse est dépeint comme un raciste, hautain et arrogant, qui considère les Juifs « un peuple consacré... parmi toutes les nations » et qui se voit lui-même destiné à régner sur eux (Deutéronome $7: 6$ et $5: 6$ ). Ces passages dans la Bible vont tellement à l'encontre de l'esprit de Moise qu'il est fort probable qu'ils aient été insérés à une date ultérieure.

De toutes manières, la fermeture des temples révèle à elle seule l'intolérance de Moïse, et cette mesure n'a même pas été efficace. Quand Horemheb devient pharaon, vingt-huit ans plus tard, le mouvement de résistance s'était tellement fortifié que Moïse se vit obligé de quitter l'Égypte avec son peuple et de le mener dans cet Exode difficile, plutôt que de renoncer entièrement à son programme.

Les souffrances du peuple juif, hélas, ne se sont pas arrêtées là. En 122120 av. J.-C., le pharaon Merenptah essaya d'anéantir l'hostile foi juive ; il s'acharna sur ce peuple si bien qu'il crut pouvoir déclarer : « Israël n'existe plus. La Palestine est devenue veuve par la main de l'Égypte». Plus tard, le christianisme et l'islam ont imité l'intolérance de l'Ancien Testament et, des siècles durant, se sont efforcés de s'anéantir mutuellement.

Nous pouvons dire maintenant, rétrospectivement, que Moïse s'est trompé lourdement en fermant les temples de l'ancienne religion. C'est peut-être sa seule grande erreur. Il aurait dû bâtir les temples d'Aton à côté des temples d'Osiris et d'Amon, et peut-être, aussi, faire arrêter quelques uns des prêtres d'Amon les plus gênants ; du moins c'est ce que nous pouvons déclarer aujourd' hui avec l'avantage du recul.

\section{Deux accomplissements de Moïse}

Moïse nous a donné le jour de repos hebdomadaire. Il a aussi créé les conseils des aînés - la première démocratie locale. Il est possible que ces deux grandes innovations aient été liées.

En effet, un jour de repos périodique laisserait aux hommes le temps, non seulement de se reposer, mais aussi de réfléchir - et, inévitablement, de critiquer. Ensuite, ces hommes formeraient sans doute des comités, bien qu'au 
début ils ne soient pas reconnus officiellement. Une fois organisée, cette classe de travailleurs unifiés pourrait même renverser l'État... à moins que l'État ne prenne les devants. Tout cela, Moïse l'aurait compris.

Si tel a été le cas, nous pouvons penser qu'il aurait établi ses omniprésents conseils des aînés en même temps que le jour de repos hebdomadaire. Soulignons que Moïse a créé un conseil, qui jouissait d'une plus grande autorité, composé de seulement soixante-dix aînés. Ce conseil, à qui il pouvait s'adresser en personne vu le nombre relativement peu élevé de ses membres, lui servait utilement d'organe de contrôle. Les idées pouvaient ainsi circuler librement dans les deux sens de la hiérarchie : de Moïse jusqu'aux échelons inférieurs et inversement. Par ailleurs, en reconnaissant tous les aînés, Moïse leur conférait une certaine dignité et les intégrait à son gouvernement.

Je dois supposer que les aînés de tous les niveaux de la hiérarchie étaient élus. Ils devaient être tout simplement trop nombreux pour que Moïse ait pu à lui seul les choisir un par un. Aujourd'hui encore, les juifs et les membres de certaines sectes chrétiennes, comme les baptistes, les congrégationalistes et les presbytériens, continuent à élire leurs aînés. De la même manière, les gouvernements locaux de l'Attique, en Grèce, étaient élus, et ce dès "l'époque de Cécrops et des premiers rois » (Thucydide, Histoire de la guerre du Péloponnèse, $2: 5: 1$ ), c'est-à-dire depuis l'époque du grand Zeus, en 1360 av. J.-C. environ.

C'est probablement à cette même époque qu'a vécu Moïse, Moïse étant Ramose, "seul compagnon " et guide du jeune pharaon Akhnaton, qui régna sur l'Égypte de 1375 à 1358 av. J.-C. Aton, le dieu, ou plutôt la " force de la nature » qu'il honorait, est devenu Adonai dans la Bible. Pendant un certain temps, un autre « nom de dieu » fut utilisé : Râ — mais ce nom fut abandonné en 1370 av. J.-C. C'est ainsi que Ramose, laissant tomber la première syllabe de son nom, s'appela dorénavant Mose ou Moïse. Notre Moïse. Ce fut Cécrops, égyptien de naissance, qui a propagé jusqu'en Attique la coutume des conseils démocratiques qui lui venait de l'Égypte de Moïse. La démocratie grecque est donc née, issue de ces conseils des aînés que Moïse avait instaurés. Et voilà donc que le don de Moïse aux hommes — le jour de repos - doit nécessairement avoir été lié à l'autre grand don qu'on lui doit, la démocratie. Ces deux bienfaits brillent comme des étoiles jumelles dans notre vie moderne.

(TraduTt Par Robert Holum ET REVISÉ PaR CHRISTINe KENNEDY)

Berkeley, USA 